\title{
THE EFFECTS OF HELIUM BUBBLE MICROSTRUCTURE ON DUCTILITY IN ANNEALED AND HERF 21Cr-6Ni-9Mn STAINLESS STEEL(U)
}

\author{
M. H. Tosten and M. J. Morgan \\ STRATEGIC MATERIALS TECHNOLOGY DEPARTMENT \\ Materials Technology Section
}

ISSUED: JANUARY, 1998

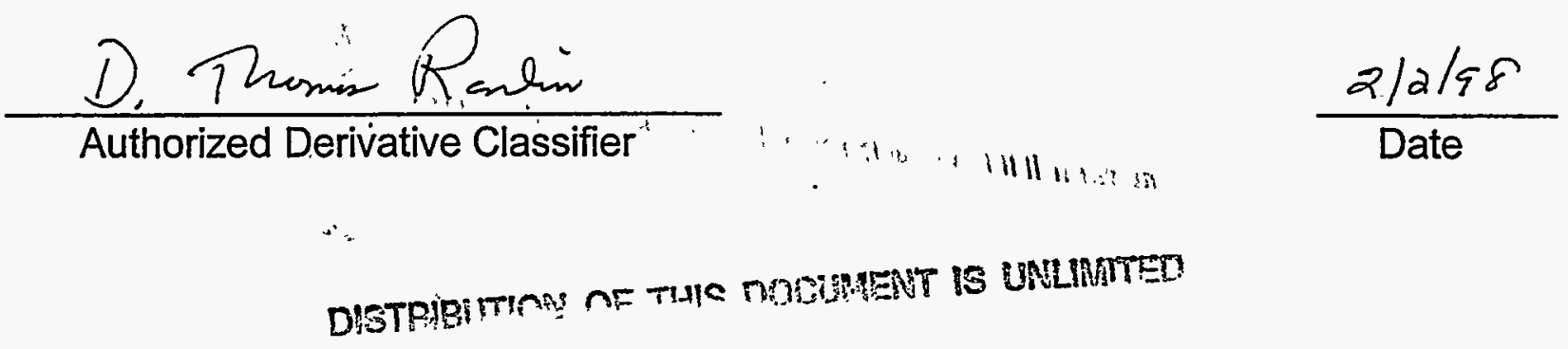

SRTC SAVANNAH RIVER TECHNOLOGY CENTER, AIKEN, SC 29808 Westinghouse Savannah River Company 
WSRC-RP-92-551

APPROVALS

M. H. Tosten, AUTHOR

Materials Compatibility \& Joining Technology Group MATERIALS TECHNOLOGY SECTION

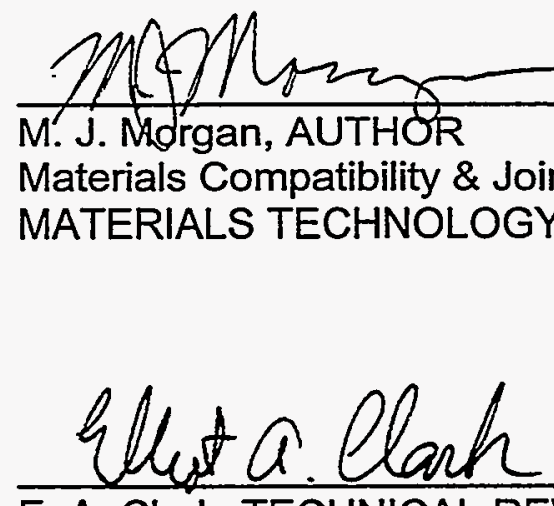

E. A. Clark, TECHNICAL REVIEWER Materials Compatibility \& Joining Technology Group MATERIALS TECHNOLOGY SECTION

D. Themes Rabin

D. T. Rankin, MANAGER

Materials Compatibility \& Joining Technology Group MATERIALS TECHNOLOGY SECTION

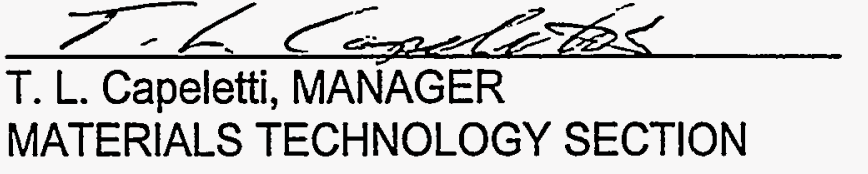

DATE: $2 / 2 / 58$

DATE: $2 / 2 / 98$

DATE: 2 Felorum 1998

DATE: $2 / 2 / 98$

DATE: $2 / 2 / 58$

ii 


\section{DISCLAIMER}

Portions of this document may be illegible electronic image products. Images are produced from the best available original document. 
INTRODUCTION.................................................................................. 1

EXPERIMENTAL PROCEDURE................................................................2

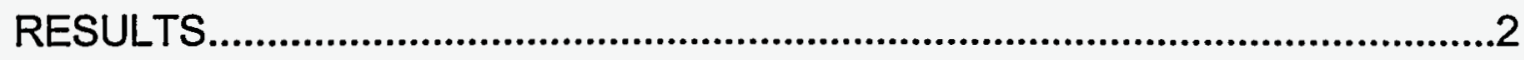

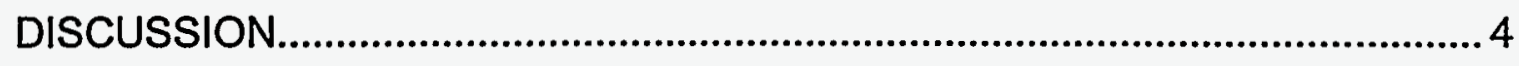

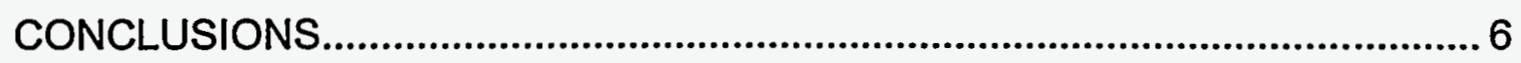

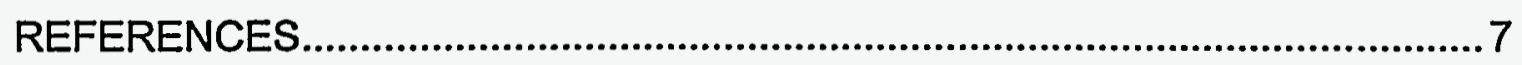

\section{TABLES}

TABLE 1 Heat Compositions and Forging Treatments..............................9 
FIGURE 1. Schematic diagram illustrating TEM specimen preparation......... 10

FIGURE 2. Engineering stress-strain curves of both hydrogen-exposed and tritium-exposed-and-aged samples.

FIGURE 3. Base microstructure of HERF and annealed $21 \mathrm{Cr}-6 \mathrm{Ni}-9 \mathrm{Mn}$ stainless steel.

FIGURE 4. The recrystallized microstructure in the elastically deformed, annealed specimen material.

FIGURE 5. The "duplex" microstructure in the elastically strained, HERF specimen material.

FIGURE 6. The helium bubble distribution in the elastically strained, annealed material.

FIGURE 7. Helium bubbles on matrix dislocations in the elastically strained, annealed specimen material.

FIGURE 8. The helium bubble distribution on a high angle grain boundary in plastically strained, annealed material

FIGURE 9. The helium bubble distribution on a grain boundary between two annealed grains in the plastically strained, HERF material..... 18

FIGURE 10. Planar slip in plastically strained, recrystallized grains of a HERF specimen.

FIGURE 11. Deformation twinning in the plastically deformed, HERF material. 


\title{
The Effects of Helium Bubble Microstructure on Ductility in Annealed and HERF 21Cr-6Ni-9Mn Stainless Steel (U)
}

\author{
M. H. Tosten and M. J. Morgan
}

\section{SUMMARY}

This study examined the effects of microstructure on the ambient temperature embrittlement from hydrogen isotopes and decay helium in $21 \mathrm{Cr}-6 \mathrm{Ni}-9 \mathrm{Mn}$ stainless steel. Hydrogen and tritium-exposed $21 \mathrm{Cr}-6 \mathrm{Ni}-9 \mathrm{Mn}$ stainless steel tensile samples were pulled to failure and then characterized by transmission electron microscopy (TEM) and optical microscopy. This study determined that ductility differences between annealed and high-energy-rate-forged (HERF) stainless steel containing tritium and its decay product, helium, could be related to differences in the helium bubble microstructures. The HERF microstructures were more resistant to tritium-induced embrittlement than annealed microstructures because the high number density of helium bubbles on dislocations trap tritium within the matrix and away from the grain boundaries.

\section{INTRODUCTION}

Tritium and deuterium reservoirs are manufactured from high-energy-rate-forged (HERF) stainless steels. The HERF process is used because it produces a near-net shape with high strength. Austenitic steels like Types $304 \mathrm{~L}$ and $21 \mathrm{Cr}-6 \mathrm{Ni}-9 \mathrm{Mn}$ are the materials of choice because of good resistance to hydrogen-induced-cracking (HIC) [14]. However, resistance to HIC decreases with increasing concentrations of helium-3 (from tritium decay) following long-term exposure to tritium gas [5]. The degree of resistance to tritium-induced-cracking varies considerably with composition $[6,7]$, yield strength, and microstructural variations associated with the HERF process [8].

An earlier study showed that tritium-charged samples with annealed microstructures had much lower ductilities than samples with HERF microstructures [9]. This was not true for samples charged only with hydrogen. It was speculated that the reason for the differences between hydrogen- and tritium-charged samples had to do with the effect of dislocations on the helium (from tritium decay) bubble microstructure.

The purpose of the present study was to use transmission electron microscopy (TEM) to characterize the helium bubble distributions in annealed and HERF $21 \mathrm{Cr}-6 \mathrm{Ni}-9 \mathrm{Mn}$ stainless steel tensile bars that had been pulled to failure. The major objective was to determine why the HERF microstructures were more resistant to tritium embrittlement than annealed microstructures. 


\section{EXPERIMENTAL PROCEDURE}

Tensile tests were conducted using samples machined from $21 \mathrm{Cr}-6 \mathrm{Ni}-9 \mathrm{Mn}$ stainless steel forgings that were supplied in the form of forward extruded cylinders. The compositions and forging treatments are listed in Table 1 . The forgings were approximately $10 \mathrm{~cm}$ long and $3.8 \mathrm{~cm}$ in diameter. The tensile samples had a $19.1 \mathrm{~mm}$ gage length and a $4.8 \mathrm{~mm}$ diameter. The forgings had been HERF to produce nominal yield strengths of $660,760,870$, and $930 \mathrm{MPa}$. A few samples from the $930 \mathrm{MPa}$ forging were subsequently annealed at $1144 \mathrm{~K}$ for 5 minutes to produce a recrystallized microstructure having a nominal yield strength of $517 \mathrm{MPa}$.

One set of samples was exposed to hydrogen at $623 \mathrm{~K}$ and $69 \mathrm{MPa}$ for 6 weeks. This treatment saturated the samples with approximately 9500 atomic parts per million (appm) hydrogen based on the available diffusivity and solubility data [3]. Another set of samples was exposed to tritium gas at $423 \mathrm{~K}$ and $31 \mathrm{MPa}$ for 9 months, and aged for 12 more months at $298 \mathrm{~K}$ to build-in helium from tritium decay. The average tritium and helium concentrations were calculated to be 2470 appm and 390 appm, respectively. The samples were pulled at room temperature in air using a screw-driven mechanical testing machine and a crosshead speed of $0.0085 \mathrm{~m} / \mathrm{s}$.

TEM specimens were prepared from both a HERF (930 MPa) and an annealed ( 517 $\mathrm{MPa}$ ) tensile bar that had been pulled to failure. Specimens were taken from the grip (elastically strained) and gauge (plastically strained) sections of each bar (Figure 1). The tensile bars were machined to a diameter of $\sim 3 \mathrm{~mm}$, a standard size for TEM specimens. Disks were sliced from each bar normal to the tensile axis. These disks were ground to $\sim 0.1 \mathrm{~mm}(0.004 \mathrm{in}$.) in thickness. Final thinning to produce electron transparent regions was performed using a twin-jet electropolisher. The electrolyte employed consisted of 4 vol\% $\mathrm{HClO}_{4}, 40$ vol\% butylcellosolve, and $56 \mathrm{vol} \%$ methanol. Jet-polishing was performed using a potential of 11 volts with the solution cooled to 258 $\mathrm{K}$. After thinning, the foils were rinsed for about 1 minute in a steady stream of ethanol. All specimens were examined in a Philips EM400T TEM operating at $120 \mathrm{kV}$.

\section{RESULTS}

Typical engineering stress-strain curves for the unexposed, hydrogen-exposed, and tritium-exposed steels are shown in Figure 2. Significant strength increases were observed for both hydrogen- and tritium-exposed steels. Helium had a bigger effect on the strengths than hydrogen on a per atom basis [9]. Unexposed and hydrogenexposed samples with the annealed microstructure had higher elongations than the samples with the HERF microstructures. In contrast, tritium-exposed-and-aged steels having the annealed microstructure had much lower elongations than the tritiumexposed HERF samples. Unexposed samples and all HERF samples charged with either hydrogen or tritium failed by a microvoid nucleation and growth process. In contrast, annealed samples that were subsequently tritium-charged-and-aged fractured brittlely along grain boundaries [9]. 
The grain structures of the samples examined by optical microscopy were also quite different (Figure 3). The unannealed, HERF sample (Figure 3a) was characterized by large, elongated grains whose boundaries were decorated with a network of small recrystallized grains. The presence of the small grains indicated the onset of recrystallization. In this specimen material much of the HERF/HERF boundary area was replaced by these small grains. The microstructure of the annealed material (Figure $3 b$ ) consisted of equi-axed grains many of which contained annealing twins. The dark "lines" at the arrows in Figure $3 \mathrm{~b}$ indicate the location of prior austenite grain boundaries that had been selectively etched because of chemical inhomogeneities at these locations.

The base microstructure of the elastically deformed, annealed specimen material was completely recrystallized as indicated by the presence of nearly dislocation-free, equiaxed grains (Figure 4). Carbides $\left(\mathrm{M}_{23} \mathrm{C}_{6}\right)$ were also observed throughout the material. In most cases these carbides indicated the position of prior, HERF austenite boundaries that most likely served as nucleation sites for the start of recrystallization. In contrast to the annealed material, the microstructure of the elastically deformed, HERF material was approximately $15 \%$ recrystallized. The "duplex" microstructure present was typical of HERF material and consisted of "patches" of $\sim 5 \mu \mathrm{m}$ in diameter recrystallized grains at the prior HERF/HERF boundaries and within the much larger, $\sim 200 \mu \mathrm{m}$, unrecrystallized grains (Figure 5). The recrystallized grains were generally dislocation-free indicating that they were formed subsequent to HERF, i.e., by a static recrystallization process.

Tritium-exposed samples featured nanometer-sized helium bubbles. The size and distribution of these bubbles was affected by the prior, base microstructure of the samples. The helium bubble microstructure found in the elastically deformed, annealed material was similar to that which was observed in the recrystallized patches in the elastically deformed, HERF material. Bubbles, measuring 1-2 $\mathrm{nm}$ in diameter, were found within the grain interiors, at the incoherent twin boundaries, and on dislocations. Figure 6 shows the helium bubble distribution within the matrix and on the incoherent twin boundaries. Bubbles are clearly evident on the incoherent twin boundary in this image but those in the matrix are obscured by strain contrast resulting from distortion of the metal lattice at the matrix/bubble interface. Dislocations were particularly potent nucleation sites for the bubbles. In the recrystallized grains few dislocations were observed, but those that were present were "decorated" with a large number of helium bubbles (Figure 7).

The nucleation of helium bubbles in the unrecrystallized regions of the elastically deformed, HERF material, was limited to the dislocations only. Small bubbles, $<1.0 \mathrm{~nm}$ in diameter, were observed on all matrix dislocations, however, the number density of bubbles per length of dislocation line was much less than that observed on dislocations in the recrystallized grains. Helium bubbles were not readily observed on the high angle grain boundaries, i.e., those boundaries between recrystallized grains, HERF and recrystallized grains, and HERF grains, in either material. In many cases, bubbles were just barely visible above the background contrast in the TEM images, particularly, on 
the boundaries between annealed grains. The size of these bubbles was estimated at $<1 \mathrm{~nm}$; however, their spatial distribution in the boundary plane could not be determined.

Plastic strain affected the pre-existing helium bubble microstructure. Contrary to the elastically strained samples, helium bubbles were readily observed on the high angle grain boundaries (Figure 8 ) in the fully recrystallized specimens and on the same type boundaries within the "patches" of recrystallized grains in the HERF material (Figure 9). These bubbles measured approximately $2.0 \mathrm{~nm}$ in diameter and, in most instances, were present in large numbers. In many regions along the boundaries the bubbles appeared to have coalesced to form small cavities (see Figures 8 and 9). Coalescence of bubbles was also observed at the incoherent twin boundaries in both specimens. In contrast, bubbles were not observed on the HERF/HERF boundaries. The bubble distribution within the matrix appeared to remain unchanged after deformation.

Following plastic deformation, the base microstructure of both specimens showed the expected increase in dislocation density. Only one deformation mode was observed in the annealed samples - intense planar slip (Figure 10). In some cases cavities were observed at the intersection of dislocation pile-ups and grain boundaries. In the HERF sample, however, two different deformation modes were observed. In the recrystallized grains, like the annealed material, deformation occurred by planar slip, whereas, in the unrecrystallized, HERF grains deformation occurred almost exclusively by deformation twinning (Figure 11).

\section{DISCUSSION}

This study investigated the effects of material microstructure on the room temperature embrittlement from hydrogen isotopes and decay helium in $21 \mathrm{Cr}-6 \mathrm{Ni}-9 \mathrm{Mn}$ stainless steel. The most significant result was that the ductility of tritium exposed-and-aged steels was greatly influenced by whether the pre-existing microstructure was annealed or HERF. The effects of tritium could not be predicted from the results of experiments on the samples charged only with hydrogen. The presence of the decay product of tritium, helium-3, in the form of nanometer-sized bubbles throughout the microstructure alters the properties of the material.

In order to understand these results several factors are considered: (1) the effect of preexisting microstructure on helium bubble distribution; (2) the effects of helium bubbles on the flow and fracture properties; (3) hydrogen interaction with the helium bubbles; and (4) the role that helium bubbles play in the hydrogen embrittlement process. These points are addressed below.

Helium is insoluble in the lattice and when it is generated in the metal from tritium decay it quickly precipitates out on vacancy clusters or other defects [e.g., 10]. Helium bubbles were observed within grain interiors (Figure 6), on dislocations (Figure 7), and on incoherent twin boundaries (Figure 6). Dislocations were particularly potent 
nucleation sites based on the density of bubbles as these locations. In fact, the cores of individual dislocations in an otherwise dislocation-free matrix were decorated by a "tube" of bubbles (Figure 7). These observations are in good agreement with the formation of helium bubbles in austenitic stainless steel following alpha implantation [11] and those reported for the formation of helium bubbles from tritium decay in vanadium [12]. The preferential nucleation of helium bubbles at dislocations may result from the locally higher tritium concentrations associated with dislocations [12]. It may also be that the strain fields of dislocations make them effective heterogeneous nucleation sites for lattice helium atoms. Whatever the mechanism for helium trapping at dislocations, the most important effect of the pre-existing microstructure on the helium bubble distributions is the high densities of helium bubbles associated with dislocations.

In the absence of matrix dislocations, grain boundaries may also serve as nucleation sites for bubbles. In the annealed microstructures, we observed very small bubbles $<1$ $\mathrm{nm}$ ) on high angle grain boundaries; however, the size of these bubbles were just at or below the limit of the resolution of the imaging technique. These bubbles were visible after a small amount of plastic strain (Figure 8). In contrast, bubbles were not visible on HERF/HERF boundaries before or after plastic strain. This apparent absence of bubbles could mean that much less helium is available to precipitate on HERF/HERF grain boundaries because of preferential nucleation on the high numbers of dislocations in the unrecrystallized grain interiors.

The flow and fracture properties are affected by the precipitation of helium bubbles. The pinning of dislocations by the bubbles causes significant strengthening. The strength increase from helium observed in this study (Figure 2) is similar to that observed by Robinson [13] for HERF $21 \mathrm{Cr}-6 \mathrm{Ni}-9 \mathrm{Mn}$. At high strains the pinning of dislocations by helium can lead to deformation by twinning [13]. In this current study, deformation by twinning was observed in the HERF samples (Figure 11) but was not observed in the annealed samples. The most likely explanation for this is that the high dislocation density present in the HERF samples prior to tensile testing effectively prevents significant dislocation movement during tensile testing and forces the material to deform by a twinning mechanism.

It is difficult to separate experimentally the embrittlement effect of hydrogen from helium without changing the helium bubble microstructure. Helium bubbles at these densities do not by themselves promote intergranular fracture [14]. In fact, samples containing helium from tritium decay, but outgassed of tritium, had higher fracture toughness and ductility than samples containing both tritium and helium $[6,14]$. Together these results indicate that the embrittlement is largely due to hydrogen and the presence of helium helps to promote hydrogen embrittlement.

Hydrogen interacts with helium bubbles because it is strongly attracted to their stress fields [15]. Abramov calculated the binding energy of hydrogen to helium to be approximately two or three times the binding energy of hydrogen to dislocations [16]. According to his model, the hydrogen is attracted towards helium bubbles due to tensile 
stress which exists around bubbles. This interaction between hydrogen and helium bubbles coupled with the most common hydrogen embrittlement models can be used to help explain why annealed microstructures are more embrittled by tritium than HERF microstructures.

The most common models for hydrogen embrittlement require a critical hydrogen concentration at a critical stress level as the criterion of fracture, based on the works of Troiano [17] and Oriani et al. [18,19]. That is, an internal interface, grain boundary, or cleavage plane will fracture in the presence of hydrogen if the local stress exceeds a critical level, the magnitude of which decreases with increasing concentrations of hydrogen on the interface. Dislocation pile-ups or deformation twin impingement on boundaries during deformation locally increase the applied stress. The large stress field associated with the tip of the pile-up or twin will attract hydrogen via stress assisted diffusion [15] and, if the concentration reaches the critical amount, the boundary will fracture.

In annealed microstructures, hydrogen in solution can easily diffuse to the tip of the pile-up until the critical amount is reached. However, in HERF microstructures a large number density of helium bubbles on dislocations will trap the hydrogen within the grain before it reaches the boundary. The local concentration at the tip of the pile-up will be less and thus a higher critical stress will be required to break open the boundary. This stress could not be reached in the HERF tensile bars before fracture by strain controlled mechanisms, like dimpled rupture, intervened. However, if the stress were high enough and/or hydrogen could diffuse to the boundary without being trapped by helium bubbles, one would expect that intergranular fracture would be observed. Intergranular fracture has been observed in hydrogen-charged HERF $21 \mathrm{Cr}-6 \mathrm{Ni}-9 \mathrm{Mn}$ pre-cracked samples [8].

\section{CONCLUSIONS}

1) Helium bubbles from tritium decay were observed in HERF and annealed samples within grain interiors, on dislocations, and on incoherent twin boundaries. Upon . plastic straining bubbles were also observed on high angle grain boundaries in annealed samples.

2) The most important effects of microstructure on the helium bubble distribution are the large number of helium bubbles associated with dislocations and the strong attraction of hydrogen with those bubbles.

3) HERF microstructures are more resistant to tritium-induced embrittlement than annealed microstructures because the high number density of helium bubbles on dislocations trap tritium within the matrix and away from the grain boundaries.

4) The effects of tritium could not be predicted from the results of experiments performed on samples charged only with hydrogen. 
WSRC-RP-92-551

\section{REFERENCES}

1. A. J. West and D,. E. Rawl, Jr., Proc. Conf. on Tritium Technology in Fission, Fusion and Isotopic Applications, Dayton, OH, May 1980, (U. S. DOE CONF-800427), American Nuclear Society, Dayton, OH, 1980, p. 69.

2. A. J. West, Jr. and M. R. Louthan, Jr., "Hydrogen Effects on the Tensile Properties of 21-6-9 Stainless Steel", Metallurgical Transactions A, 1982, vol. 13A, p. 2049.

3. G. R. Caskey, Jr., "Hydrogen Effects in Stainless Steels", Hydrogen Degradation of Ferrous Alloys, J. P. Hirth, R. W. Oriani, and M. Smialowski, eds., Noyes Publication, Park Ridge, NJ, 1985, p. 822.

4. D. G. Ulmer and C. J. Altstetter, "Mechanism For Hydrogen Embrittlement of Austenitic Stainless Steels", Proc. Fourth Int. Conf. on Hydrogen Effects on Material Behavior, A. W. Thompson and N. R. Moody, eds., The Minerals, Metals \& Materials Society, Warrendale, PA, 1989, p. 421.

5. G. R. Caskey, Jr., "Tritium-Helium Effects in Metals", Fusion Technology, Vol. 8, 1985, pp. 2293-2298.

6. M. J. Morgan and M. H. Tosten, "Tritium and Decay Helium Effects on the Fracture Toughness Properties of Types 316L, 304L, and 21 Cr-6Ni-9Mn Stainless Steels", Hydrogen Effects in Materials, A. W. Thompson and N. R. Moody, eds., TMS, Warrendale, PA, 1996, p. 873.

7. B. C. Odegard, J. A. Brooks, and A. J. West, "The Effect of Hydrogen on the Mechanical Behavior of Nitrogen Strengthened Stainless Steel", Effect of Hydrogen on the Behavior of Materials, A. W. Thompson and I. M. Bernstein, eds., The Metallurgical Society of AIME, 1976, p. 116.

8. M. J. Morgan and M. H. Tosten, "Microstructure and Yield Strength Effects on Hydrogen and Tritium Induced Cracking in HERF Stainless Steel", Hydrogen Effects on Material Behavior, N. R. Moody and A. W. Thompson, eds., TMS, Warrendale, PA, 1990, pp. 447-457.

9. M. J. Morgan "The Effects of Hydrogen Isotopes and Helium on the Flow and Fracture Properties of 21-6-9 Stainless Steel", Proc. Fine Symposium, P. K. Liaw, J.R. Weertman, H. L. Marcus, and J. S. Santner, eds., TMS, Warrendale, PA, 1990, pp. 105-111.

10. G. J. Thomas, "Experimental Studies of Helium in Metals", Radiation Effects, 1983 , vol. 78, p.37.

11. W. Kesternich, "Helium Trapping at Dislocations, Precipitates, and Grain Boundaries", Radiation Effects, 1983, vol. 78, p. 261. 
12. W. Jager, R. Lasser, T. Schober, and G. J. Thomas, "Formation of Helium Bubbles and Dislocation Loops in Tritium-Charged Vanadium" Radiation Effects, 1983, vol. 78, p.165.

13. S. L. Robinson, "The Effects of Tritium on The Flow and Fracture of Austenitic Stainless Steels", Proc. Fourth Int. Conf. on Hydrogen Effects on Material Behavior, A. W. Thompson and N. R. Moody, eds., The Minerals, Metals \& Materials Society, Warrendale, PA, 1989, p. 433.

14. S. L. Robinson, "Tritium and Helium Effects on Plastic Deformation in AISI 316 Stainless Steel", Materials Science and Engineering, 1987, vol. 96, p. 7.

15. J. C. M. Li, R. A. Oriani, and L. S. Darken, Z. Phys. Chem. vol. 76, 1972, p. 848.

16. E. Abramov and D. Eliezer, "Synergistic Effects of Helium and Hydrogen Isotopes", Proc. Fourth Int. Conf. on Hydrogen Effects on Material Behavior, A. W. Thompson and N. R. Moody, eds., The Minerals, Metals \& Materials Society, Warrendale, PA, 1989, p. 169.

17. A. R. Troiano, Transactions of ASM, 1960, vol. 52. p. 54.

18. R. A. Oriani, Ber-Bunsen-Geselsch. Phys. Chem. (N. F.), 1972, vol. 76, p. 848.

19. R. A. Oriani and P. H. Josephic, Acta Metallurgica, 1974, vol. 22, p. 1065. 


\section{TABLE 1}

\section{Heat Compositions and Forging Treatments}

Heat Compositions (wt. \%)

\begin{tabular}{lcccccccccc}
\hline Heata & $\mathrm{Cr}$ & $\mathrm{Ni}$ & $\mathrm{Mn}$ & $\mathrm{P}$ & $\mathrm{Si}$ & $\mathrm{C}$ & $\mathrm{S}$ & $\mathrm{N}$ & O(wppm) & $\mathrm{Al}$ \\
1 & 19.2 & 7.22 & 9.23 & .014 & .41 & .032 & .003 & .28 & 19 & .002 \\
2 & 19.4 & 6.40 & 8.50 & .021 & .33 & .040 & $<.001$ & .28 & 22 & $<.001$ \\
3 & 20.1 & 6.50 & 9.10 & .019 & .59 & .037 & $<.001$ & .29 & 10 & .001 \\
\hline
\end{tabular}

a Heat 1 was used for forgings of nominal yield strengths of 660 and $760 \mathrm{MPa}$. Heat 2 was used for forgings of nominal yield strengths of 760 and $870 \mathrm{MPa}$. Heat 3 was used for forgings of nominal yield strengths of $930 \mathrm{MPa}$.

Forging Conditions: Extrusion die and stub punch; heat parts to $1255 \mathrm{~K} \pm 10 \mathrm{~K}$; hold for 10 to 15 minutes; forge 1 blow at $2 \mathrm{MPa} \pm .17 \mathrm{MPa}$; water quench; heat to $1116 \mathrm{~K} \pm 10$ $\mathrm{K}$; forge 1 blow at $5.5 \mathrm{MPa} \pm .17 \mathrm{MPa}$; water quench. .

Annealing Conditions: (Nominal Yield Strength of $517 \mathrm{MPa}$ ): $1114 \mathrm{~K}$ for 5 minutes. 


\section{TEM Specimens from Tensile Bars}

(1)
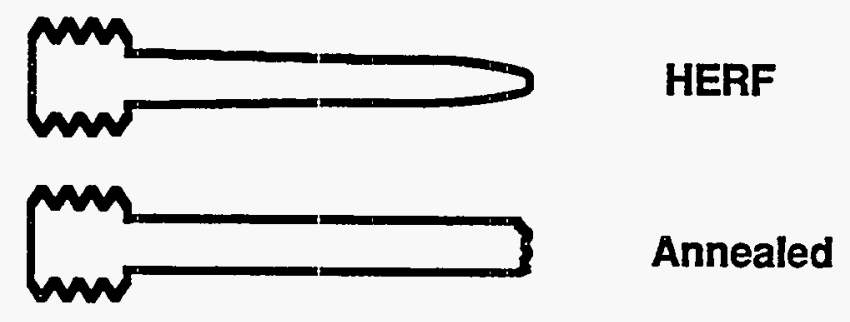

(2)

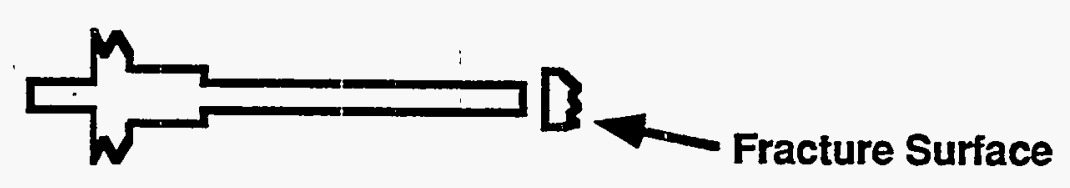

(3)

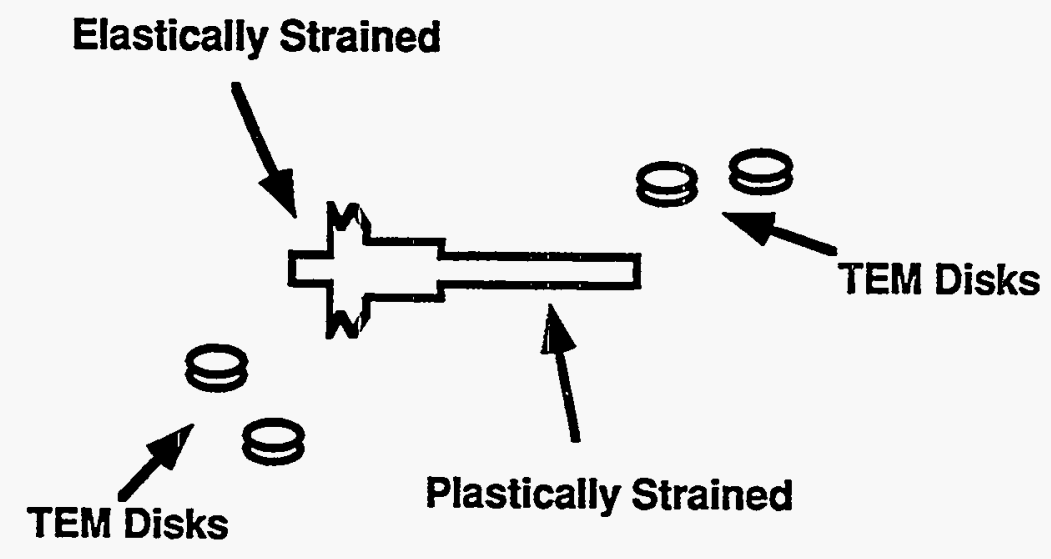

Figure 1. Schematic diagram illustrating how TEM specimens were sectioned from the HERF and annealed tensile bars. 


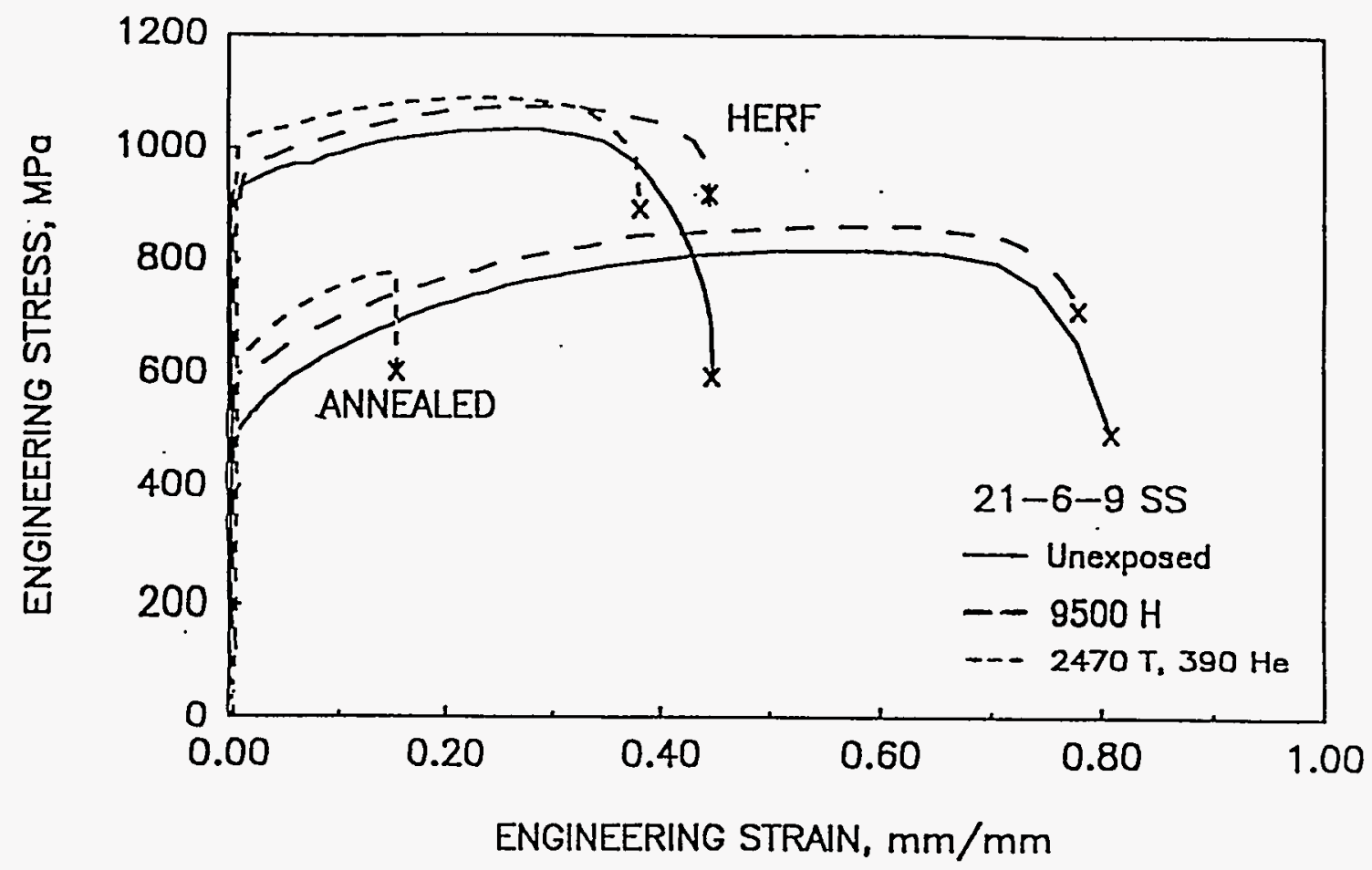

Figure 2. Engineering stress-strain curves showing that significant strengthening occurred for both hydrogen-exposed and tritium-exposed-and-aged samples. Tritium-exposed-and-aged steels having an annealed microstructure had much lower elongations than the other samples. 

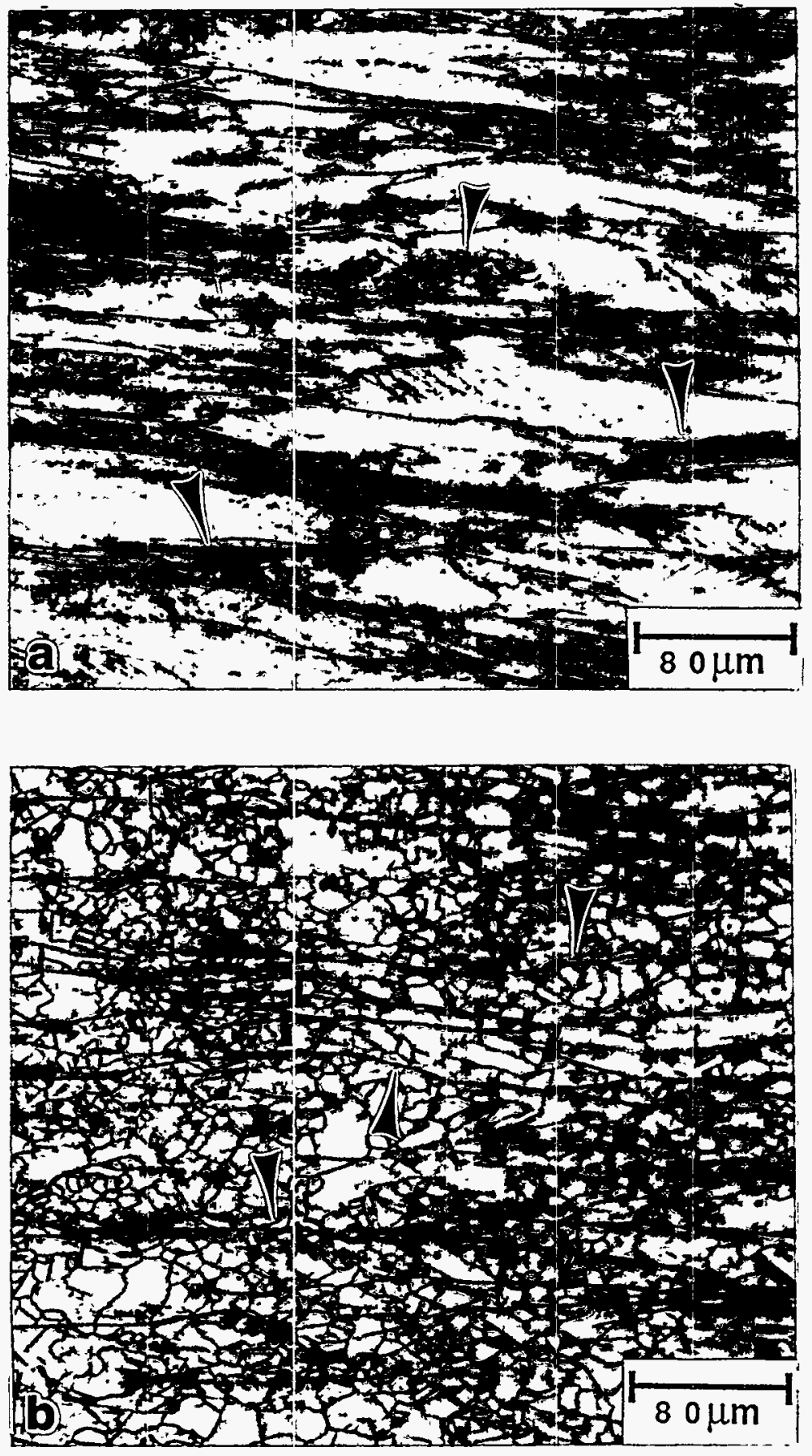

Figure 3. Representative longitudinal sections showing the base microstructure of the $21 \mathrm{Cr}-6 \mathrm{Ni}-9 \mathrm{Mn}$ stainless steel: (a) HERF; (b) annealed. The arrows in (a) indicate the location of small, recrystallized grains on the HERF/HERF boundaries while those in (b) denote the positions of prior austenite grain boundaries. 


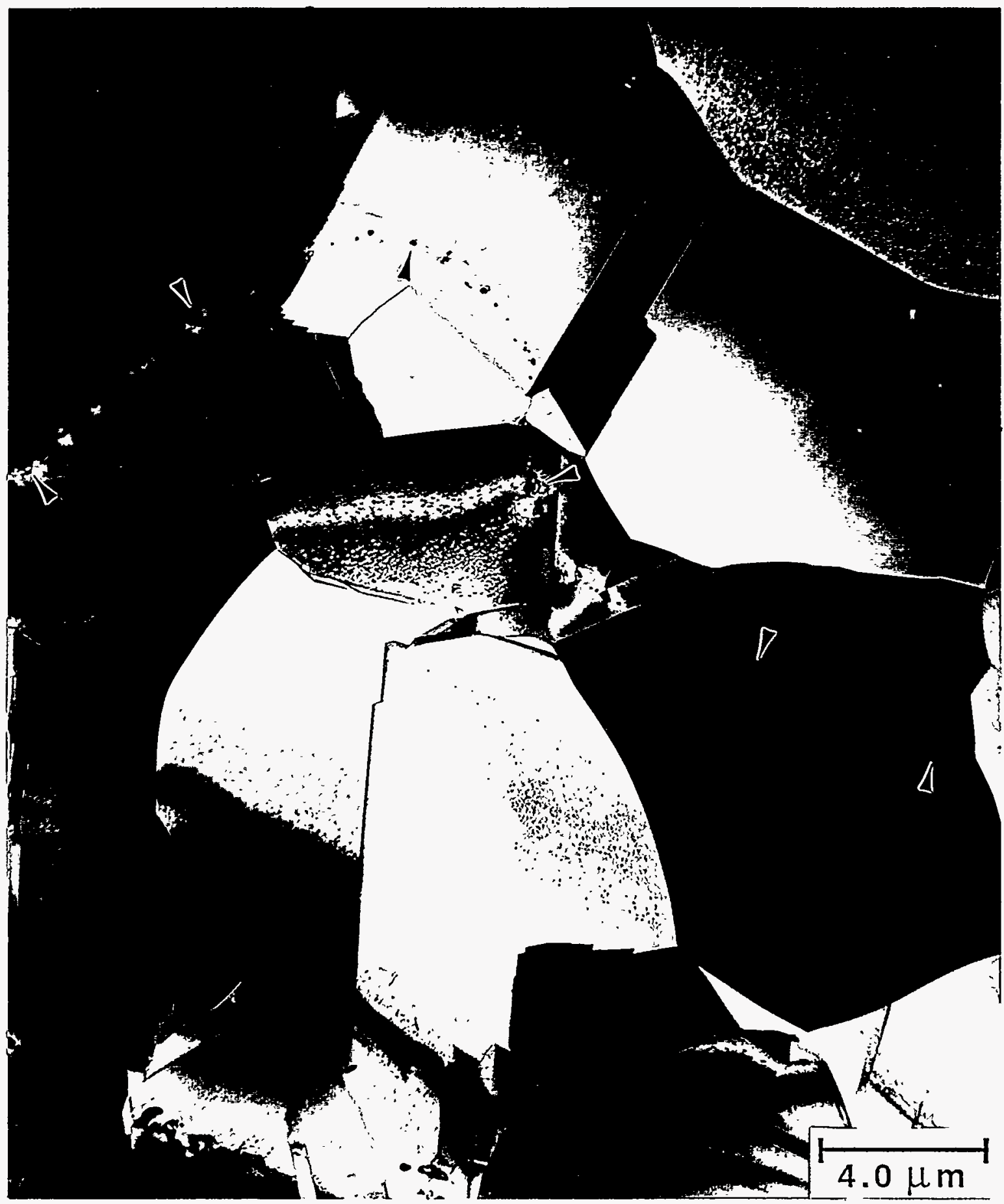

Figure 4. The recrystallized microstructure of the elastically deformed, annealed specimen material. Carbide precipitates, e.g., at arrows, mark the location of a prior austenite grain boundary. 


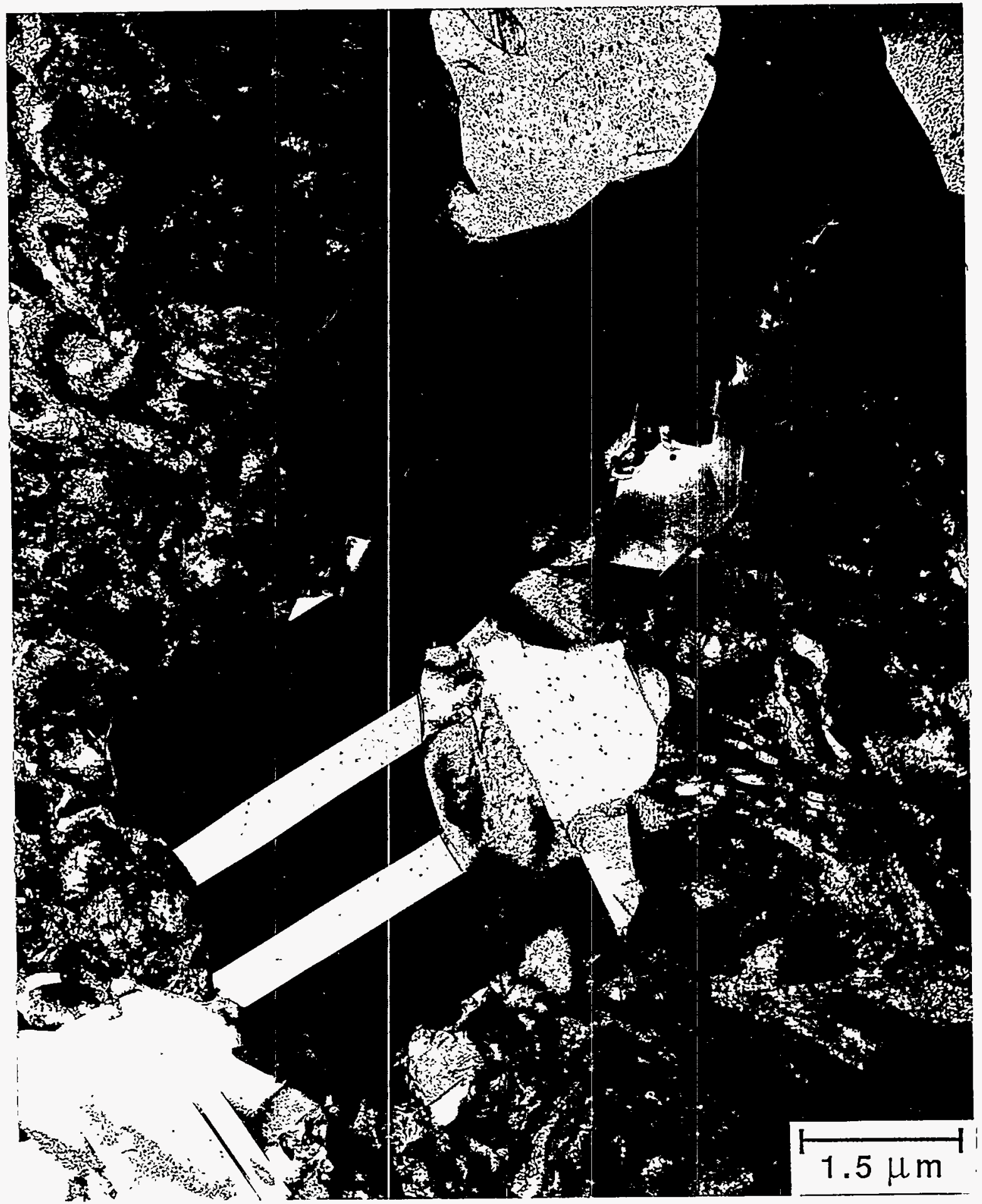

Figure 5. The "duplex" microstructure of the elastically strained, HERF specimen material. Patches of recrystallized grains have formed within the unrecrystallized, HERF grains. 


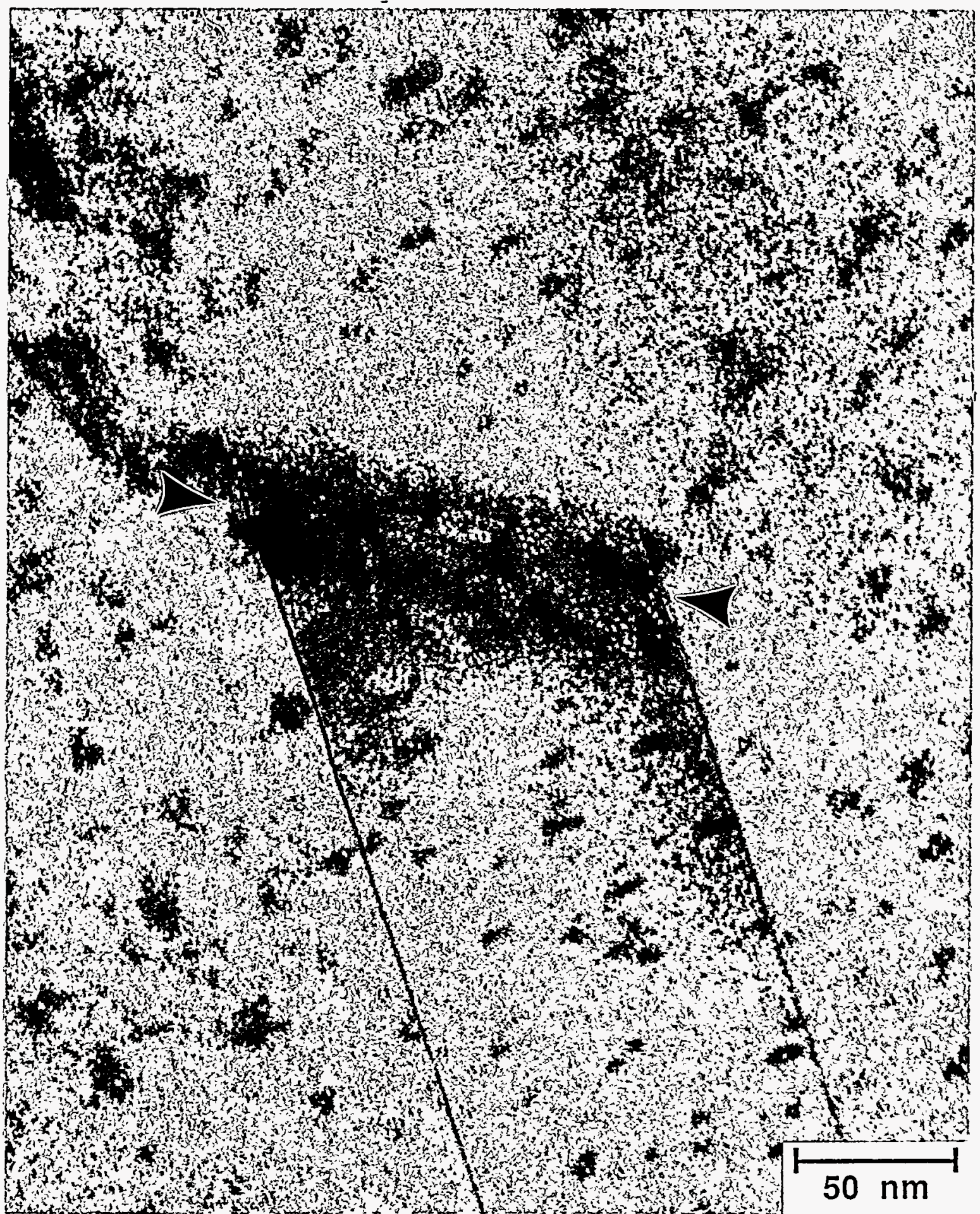

Figure 6. The helium bubble distribution within a recrystallized grain in the elastically strained, annealed material. Bubbles have nucleated in the matrix (dark spots with white centers) and on an incoherent twin boundary (at arrows). 


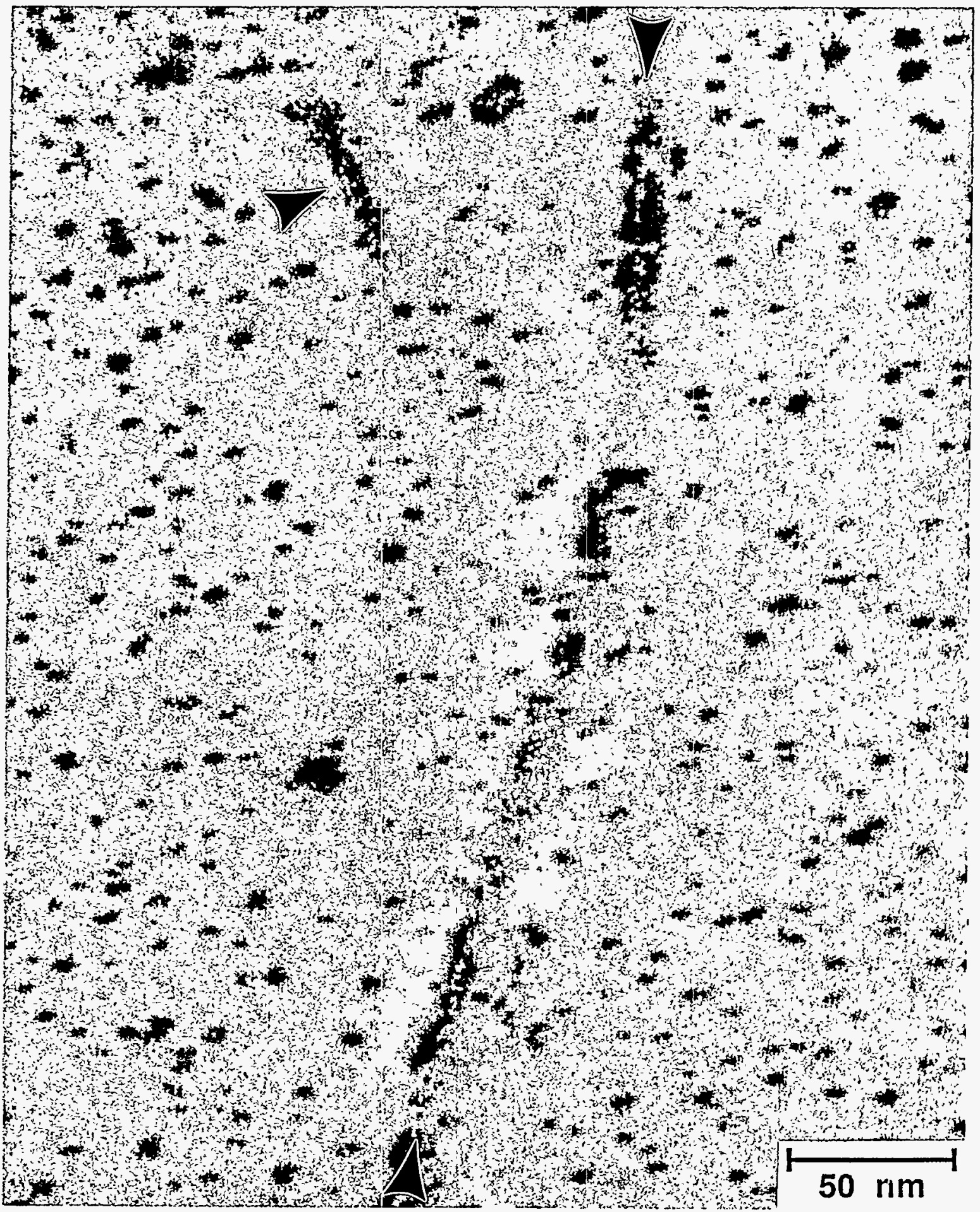

Figure 7. Helium bubbles on matrix dislocations (at arrows) in the elastically strained, annealed specimen material. The strain fields from homogeneously nucleated bubbles are visible as black spots in the surrounding matrix. 


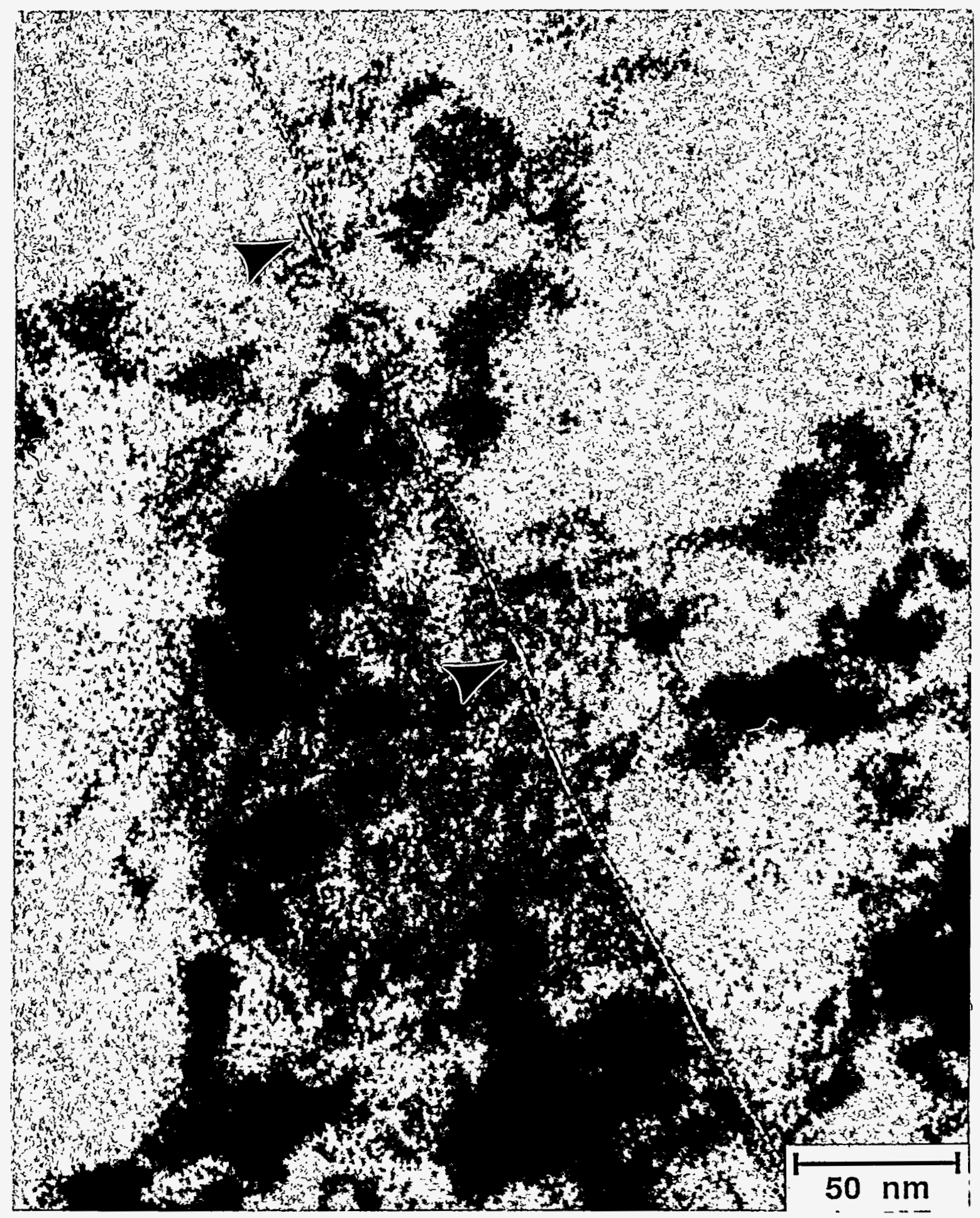

Figure 8. The helium bubble distribution on a high angle grain boundary in the plastically strained, annealed material. In some places the bubbles appeared to have coalesced to form small cavities, e.g., at arrows. 


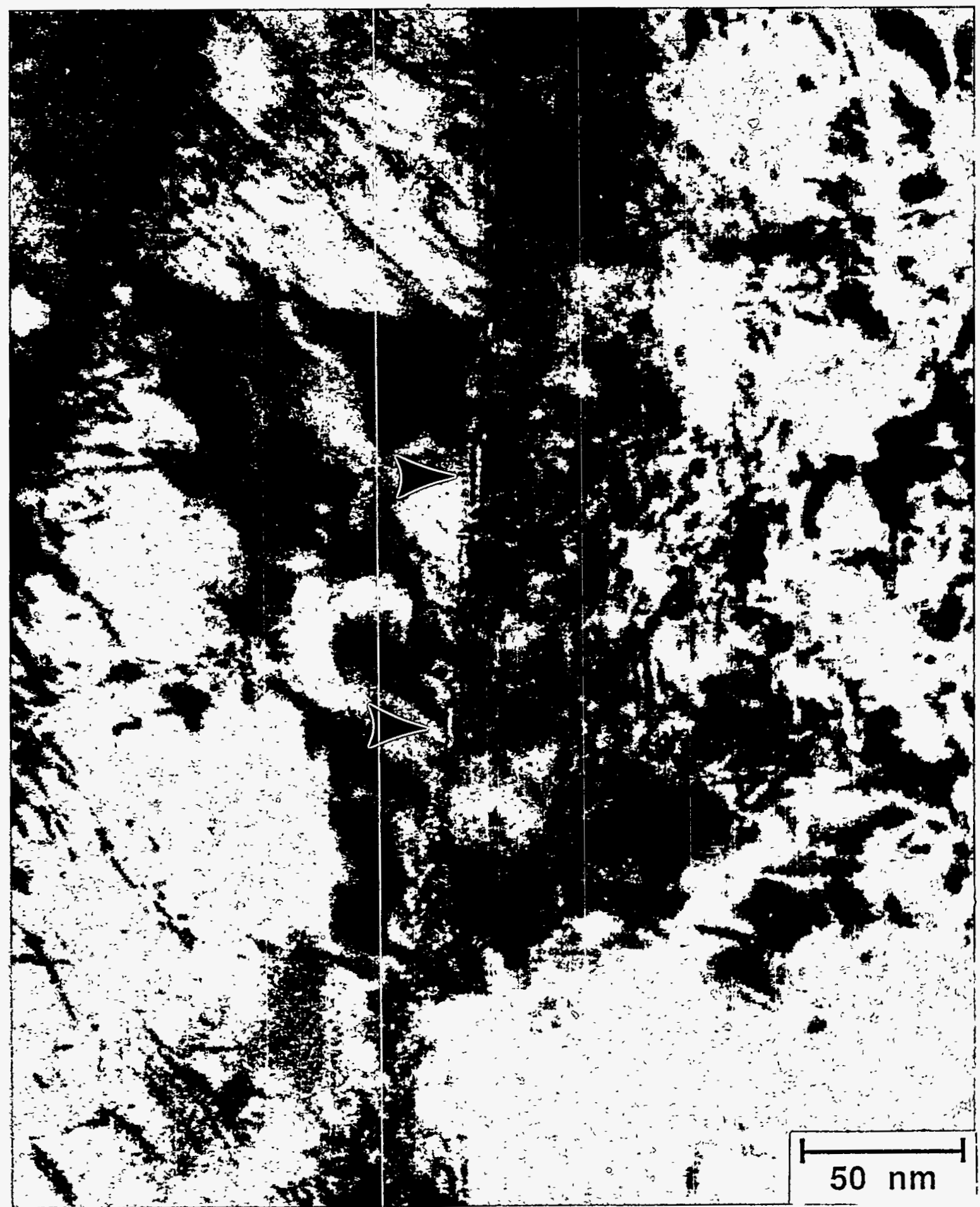

Figure 9. The helium bubble distribution on a grain boundary between two annealed grains in the plastically strained, HERF material. As in Figure 8, coalescence of bubbles has occurred in some locations along this boundary (at arrows). 


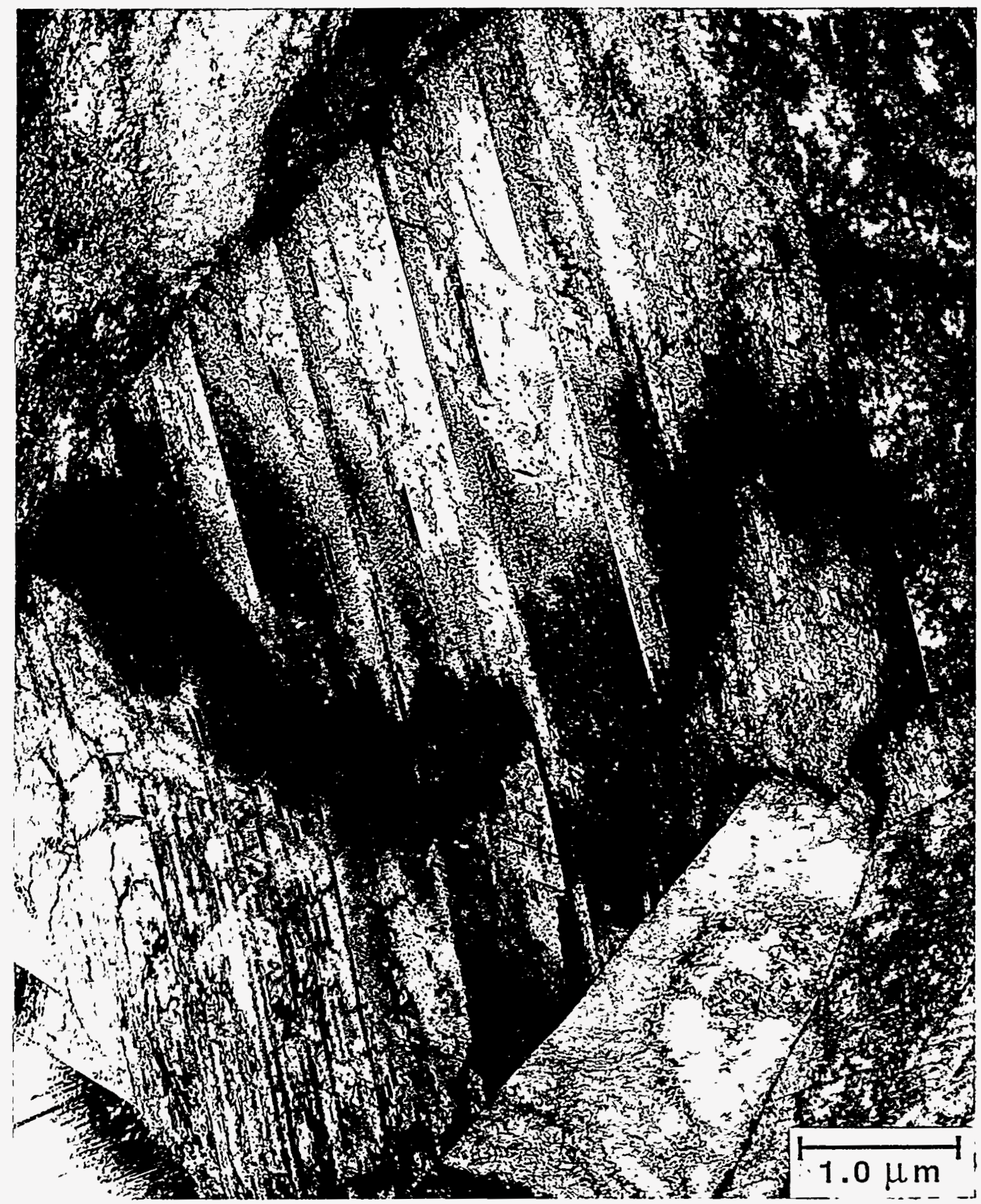

Figure 10. Planar slip in the plastically strained, recrystallized grains of a HERF specimen. This deformation mode was also observed in the plastically strained, annealed specimens. 


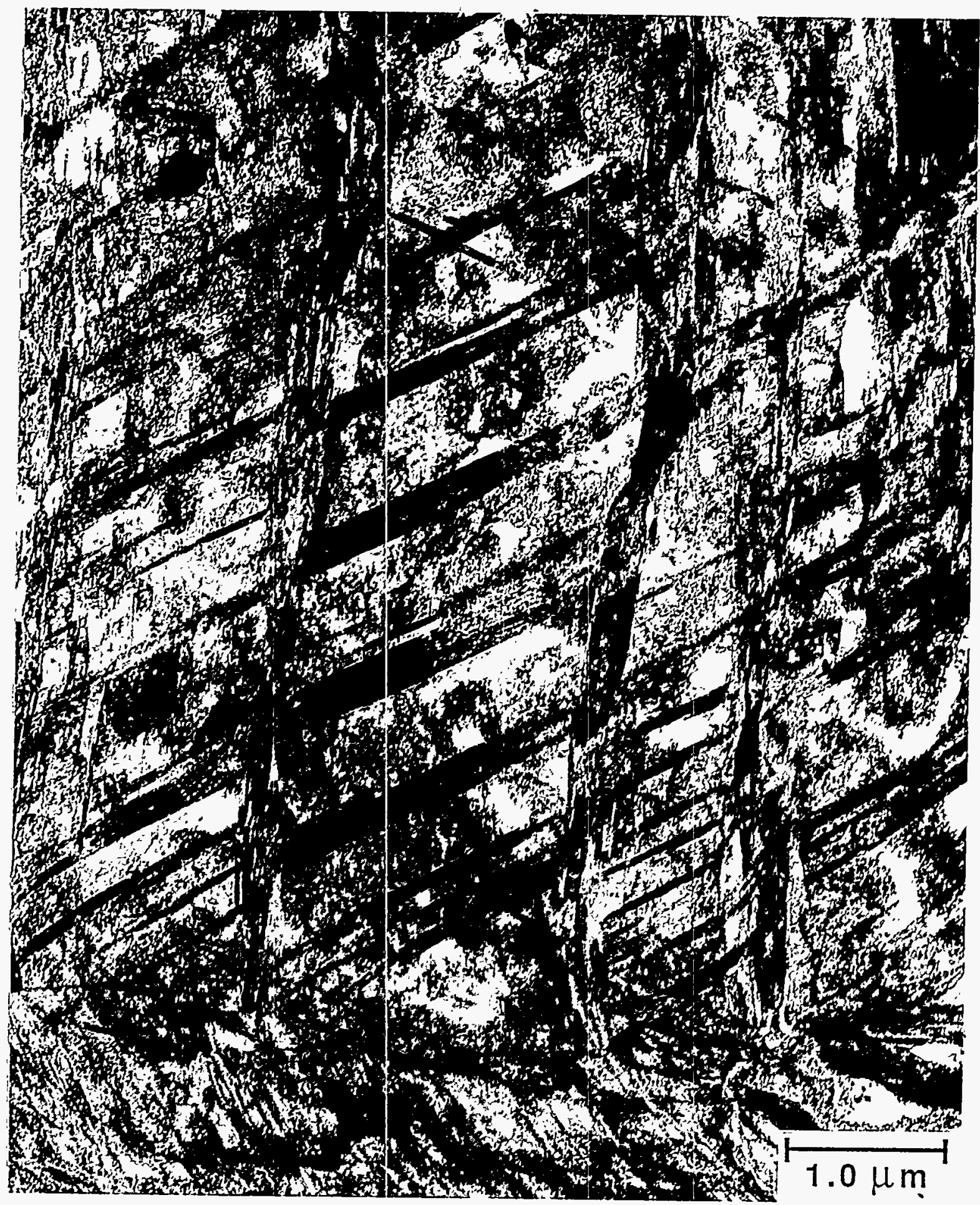

Figure 11. Deformation twinning in the plastically deformed, HERF material. 